\title{
NUTRITIONAL AND ANTIOXIDANT PROPERTIES OF SELECTED TRADITIONAL RICE (Oryza sativa L.) VARIETIES OF SRI LANKA
}

Samaranayake M.D.W. ${ }^{1}$, Yathursan S. ${ }^{2}$, Abeysekera W.K.S.M. ${ }^{*}$, and Herath H.M.T. ${ }^{1}$

${ }^{1}$ Food Technology Section (FTS), Modern Research \& Development Complex (MRDC), Industrial Technology Institute (ITI), 503A, Halbarawa Gardens, Malabe, Sri Lanka.

${ }^{2}$ School of Chemical Sciences, University of Auckland, Auckland 114, New Zealand.

DO1: http://doi.org/10.4038/s1jb.v2i2.10

\begin{abstract}
Five traditional red and white rice varieties of Sri Lanka namely Kurulu Thuda, Nilkanda, Heeneti, MaaWee and Suwadal were studied for a range of nutritional and antioxidant properties (AP). Whole grain flour of the selected varieties were studied for moisture, crude fat, crude protein, crude ash, available carbohydrates, total dietary fiber (TDF) and sugar contents using standard analytical techniques $(n=3)$, while oil extracted from rice bran was studied for the fatty acid profile using gas chromatographic technique $(n=3)$. Antioxidant properties were studied using ferric reducing antioxidant power (FRAP) and 2-azino-bis (3-ethylbenzothiazoline-6-sulfonic) acid (ABTS) radical scavenging activity for the $70 \%$ ethanolic extracts of the rice bran $(\mathrm{n}=3$ each). Results showed significant $(\mathrm{P}<0.05)$ differences for both nutritional and AP among the varieties tested. However, between red and white rice varieties variation was significant $(\mathrm{P}<0.05)$ only for the AP. Among the selected varieties, Suwadal had the highest TDF, Heeneti had the highest crude ash content while Maa Wee had the highest protein and sugar contents. Both Suwadal and Kurulu Thuda showed the highest fat content. Oleic acid was the most predominant fatty acid in all rice bran oil types. The highest oleic and palmitic acids were observed in Kurulu Thuda while MaaWee had the highest linoleic acid content. For AP, the highest activities for both FRAP and ABTS radical scavenging activity was observed for the red rice variety Kurulu Thuda while white rice variety Suwadal had the lowest. In conclusion, nutritional and AP vary significantly among the varieties and only AP varies significantly between the red and white rice types.
\end{abstract}

Key words: Nutritional and antioxidant properties, fatty acid profile, traditional rice, Sri Lankan rice, red and white rice, rice bran

*Corresponding author: Tel: +94-11-2379800; E-mail: kancha@iti.lk

(iD) http://orcid.org/0000-0002-7023-3112

This is an open-access article distributed under the terms of the Creative Commons Attribution License, which permits unrestricted use, distribution, and reproduction in any medium, provided the original author and source are credited. 


\section{Introduction}

Rice which, belongs to the genus Oryza is one of the principal cereal grains cultivated globally. Oryza sativa is the main cultivating rice species (Dogara \& Jumare, 2014) which comprises of more than 40,000 varieties of rice (Anonymous, 2011). Large numbers of high yielding varieties were developed with the establishment of the International Rice Research Institute and nearly $70 \%$ of the world's rice lands are occupied by new improved varieties (Khush, 1997). The global rice production is around 738.8 million tonnes (Rice Market Monitor FAO, 2016) and more than $90 \%$ of the world's rice is produced and consumed in the Asian region (Dutta et al., 2012), where rice being the staple food. In such countries, rice remains as the main source of dietary energy and protein for consumers. Rice bran or the outer layer of the rice grain contains more monounsaturated fatty acids (MUFAs) and polyunsaturated fatty acids (PUFAs) and also a rich source of nutrients (Gunaratne et al., 2013). MUFAs and PUFA plays a vital role in maintaining cholesterol level in the human body and reduce the risk of heart diseases (Fernandez \& West, 2005; Orsavova et al., 2015). Furthermore, rice bran especially the pigmented rice bran is a rich source of variety of phytochemicals including naturally occurring antioxidants (Gunaratne et al., 2013).

In Sri Lanka, rice is the dietary staple (Rajapakse et al., 2000; Gunaratne et al., 2013). The high yielding new improved rice varieties developed by the Department of Agriculture, Sri Lanka are currently cultivating island wide. However, up to 1950 s the rice varieties cultivated in the country were exclusively traditional varieties. It is reported that there were thousands of traditional rice varieties which had been in the diet for centuries (Rajapakse et al., 2000; Kennedy \& Burlingame, 2003). Some of these varieties were claimed to have medicinal properties according to the Sri Lankan ethno medicine and folklore (Dharmasena, 2010; Abeysekera \& Premakumara, 2016). These health claims including some nutritional and antioxidant properties were scientifically proven in recent studies (Premakumara et al., 2013; Abeysekera et al., 2015a; Abeysekera et al., 2015b; Abeysekera \& Premakumara, 2016) and thus such traditional rice varieties currently have a good market value (Wickramasinghe \& Noda, 2008; Suriyagoda et al., 2011). However, there are numerous varieties yet to be studied. Moreover, fatty acid profile of traditional rice varieties of Sri Lanka is poorly documented. This study evaluated nutritional and antioxidant properties of selected traditional rice varieties of Sri Lanka.

\section{Material and Methods}

\subsection{Grain samples}

Five whole grain traditional rice (Oryza sativa) varieties of Sri Lanka namely Suwadal, Nilkanda, Heeneti, Ma Wee and Kurulu Thuda obtained from Weera Gamunu (Pvt) Ltd, Sri Lanka were used.

\subsection{Chemicals and reagents}

Heat stable $\alpha$-amylase from Bacillus licheniformis, pepsin from porcine gastric mucosa, pancreatin from porcine pancreas, Trolox, 2,2'-azino-bis(3ethylbenzothiazoline-6-sulfonic acid) 
diammonium salt (ABTS), SUPELCO standard fatty acid methyl ester mix and 2,4,6-tripyridyl-s-triazine (TPTZ) were purchased from Sigma-Aldrich, USA. All the other chemicals used for the preparation of buffers and solvents were of analytical grade.

\subsection{Sample preparation}

Whole grains of each of the selected rice varieties were milled using a milling machine (Universal mill PE 402, Bauermeister, Germany) fitted with a 0.25 $\mathrm{mm}$ sieve to obtain rice flour. Rice bran was obtained by polishing whole grains using a laboratory mill (TM-05C, Satake, Hiroshima, Japan) and passing through a 60 mesh sieve.

\subsection{Nutritional properties of selected Sri Lankan traditional rice}

\subsubsection{Proximate composition}

Proximate composition of selected rice varieties was studied for whole grain rice flour. The moisture, crude ash and crude fat contents were determined according to the methods described in Association of Official Analytical Chemists (AOAC), 2000. Crude protein content was estimated by the Kjeldhal method described in the operating manual (UDK 139) of Velp Scientifica which was adapted from AOAC, 2000. The total carbohydrate content was determined by the difference from the analysis of crude ash, crude fat and crude protein contents. Total available carbohydrate content was determined by the difference from the total carbohydrate from total dietary fiber (will be discussed in the following section). Analysis were carried out in triplicates $(n=3)$ for each rice variety.

\subsubsection{Total dietary fiber}

Total dietary fiber content was estimated by enzymatic gravimetric method described by Asp et al. (1983). One gram of rice flour (nearest $0.1 \mathrm{mg}$ ) was added to $25 \mathrm{~mL}$ of $0.1 \mathrm{M}$ sodium phosphate buffer $(\mathrm{pH}=6)$. Then, $100 \mu \mathrm{L}$ of heat stable $\alpha$-amylase was added and incubated in a boiling water bath for 15 min. The digest was allowed to cool, $\mathrm{pH}$ was adjusted to $1.5 \pm 0.1$ using $\mathrm{HCl}$ and added with $100 \mathrm{mg}$ of pepsin. Then samples were incubated at $40{ }^{\circ} \mathrm{C}$ for $1 \mathrm{~h}$ with agitation. After the digestion, samples were allowed to cool, $\mathrm{pH}$ was adjusted to $6.8 \pm 0.1$ with $\mathrm{NaOH}$ and incubated at $40{ }^{\circ} \mathrm{C}$ for $1 \mathrm{~h}$ with agitation with the addition of $100 \mathrm{mg}$ of pancreatin. Finally, $\mathrm{pH}$ of the samples was adjusted to 4.5 with $1 \mathrm{M} \mathrm{HCl}$ and whole digest was directly precipitated with 4 volumes of $95 \%$ ethanol and filtered through a dry and weighed crucible (porosity 2) containing $0.5 \mathrm{~g}$ of dry celite as the filter aid. Residue was washed with $2 \times 10 \mathrm{~mL}$ of $78 \%$ ethanol, $2 \times 10 \mathrm{~mL}$ of $95 \%$ ethanol and $2 \times 10 \mathrm{~mL}$ of acetone. Residue was dried at $105{ }^{\circ} \mathrm{C}$ overnight to a constant weight and weighed after cooling in a desiccator. It was incinerated at $550{ }^{\circ} \mathrm{C}$ until a constant weight was obtained. Nitrogen in the dietary fiber fractions was determined with the Kjeldahl method and transferred to protein by multiplication with 6.25 (indigestible proteins). The blank was assayed in the same way without the sample. The indigestible protein is subtracted from the dietary fiber values to calculate total dietary fiber content of the rice samples. The analysis for each rice variety was carried out in triplicates $(n=3)$. 


\subsubsection{Total sugars}

The rice flour was extracted by ethanol: water extraction method as described by Ranganna (1986). Five grams of rice flour from each variety was extracted twice with 80:20 ethanol: water $(\mathrm{v} / \mathrm{v})$ by refluxing for $30 \min (n=3)$. Combined ethanol fractions were evaporated under vacuum in a rotary evaporator. Finally, the volume of water extractions were made up to $50 \mathrm{~mL}$ (solution $\mathrm{A}$ ) and used to determine the total sugar content by phenol-sulphuric method as described by Dubois et al. (1956). Briefly, an aliquot of solution A $(2.0 \mathrm{~mL})$ was mixed with 1.0 $\mathrm{mL}$ of $5 \%(\mathrm{w} / \mathrm{v})$ phenol solution and $5 \mathrm{~mL}$ of concentrated sulphuric (95\%) acid. Then, the mixture was incubated for 20 min in a water bath at $30{ }^{\circ} \mathrm{C}$ and absorbance was measured at $490 \mathrm{~nm}$ using UV-Visible spectrophotometer (UV1601, Shimadzu, Japan). Anhydrous glucose purchased from Sigma Aldrich was used as the standard. The analysis was carried out in triplicates $(n=3)$ for each rice variety.

\subsubsection{Fatty acid profile}

Twenty gram of rice bran was extracted with petroleum ether (B.p $40-60{ }^{\circ} \mathrm{C}$ ) by solvent extraction method. Then, extracts were evaporated using a steam bath and dried in an oven (UFE 500, Memmert, Germany) at $80{ }^{\circ} \mathrm{C}$ until constant weight was obtained. The resulting oil samples were used in the analysis of fatty acid profile. Methyl esters of fatty acids were prepared by esterification method (ISO, 1978) by derivertizing with methanolic $\mathrm{KOH}$. Derivertized fatty acids were then filtered through a syringe filter (Nylon 25 $\mathrm{mm}, 0.45 \mu \mathrm{m}$ ) and analyzed using gas chromatography (ISO, 1990). A gas chromatograph (GC-2010, Shimadzu,
Japan) equipped with flame ionization detector (FID) was used for the analysis. Chromatographic separation of methyl esters were carried out on a SUPELCO SP2330 capillary column $(30 \mathrm{~m} \times 0.25 \mathrm{~mm}$, $0.25 \mu \mathrm{m})$. Nitrogen was used as the carrier gas. Injection volume of $1.0 \mu \mathrm{L}$ with a split ratio of 15:1 was used. Injector port temperature was set at $250{ }^{\circ} \mathrm{C}$. A gradient temperature program with an initial temperature of $80^{\circ} \mathrm{C}$ and a final temperature of $165^{\circ} \mathrm{C}$ was used to achieve the separation of fatty acid methyl esters. Detector temperature was set at $260^{\circ} \mathrm{C}$. The SUPELCO standard fatty acid methyl ester mix was used as the reference standard. The analysis was carried out in triplicates $(n=3)$ for each rice variety.

\subsection{Antioxidant properties of selected Sri Lankan traditional rice}

\subsubsection{Extraction of rice bran}

One gram of rice bran of each of the rice varieties were extracted with 10 times the sample weight of $70 \%$ ethanol-water $(\mathrm{v} / \mathrm{v})$ overnight at room temperature $(28$ $\pm 2{ }^{\circ} \mathrm{C}$ ). Then, extracts were centrifuged (825 g, $10 \mathrm{~min}$ ), evaporated using a rotary evaporator and freeze dried (Christ-Alpha 1-4 Freeze dryer, Biotech International, Germany). The freeze dried extracts were used in evaluation of antioxidant properties.

\subsubsection{Ferric reducing antioxidant power (FRAP) of rice bran}

Experiment was carried out according to the method of Benzie \& Szeto (1999) with some modifications in 96-well microplates $(n=6)$. The working FRAP reagent was produced just before the analysis by mixing $300 \mathrm{mM}$ acetate buffer ( $\mathrm{pH}$ 3.6), 
$10 \mathrm{mM}$ TPTZ solution and $20 \mathrm{mM}$ $\mathrm{FeCl}_{3} \cdot 6 \mathrm{H}_{2} \mathrm{O}$ in a ratio of $10: 1: 1$. Then the mixture was heated to $37^{\circ} \mathrm{C}$. The TPTZ solution was prepared by making a solution of $10 \mathrm{mM}$ TPTZ in $40 \mathrm{mM} \mathrm{HCl}$. Reaction volume of $200 \mu \mathrm{L}$ containing $150 \mu \mathrm{L}$ working FRAP reagent, $30 \mu \mathrm{L}$ acetate buffer and $20 \mu \mathrm{L}$ of rice bran extract were incubated at room temperature for $8 \mathrm{~min}$. The absorbance readings were measured at $600 \mathrm{~nm}$. Results were expressed as mmol Trolox per $100 \mathrm{~g}$ dry weight of rice bran.

\subsection{3 $\mathrm{ABTS}^{+}$radical scavenging activity of rice bran}

The $\mathrm{ABTS}^{+}$radical scavenging assay was performed according to the method described by Re et al. (1999) in 96-well micro-plates. A stable stock solution of ABTS radical was produced by reacting $7.8 \mathrm{mM}$ of ABTS in potassium persulfate at $37^{\circ} \mathrm{C}$ for $16 \mathrm{~h}$ in dark. Reaction volume of $200 \mu \mathrm{L}$, containing $40 \mu \mathrm{L}$ of seven times diluted ABTS stock solution and different concentrations of rice bran extracts were incubated at $25 \pm 2{ }^{\circ} \mathrm{C}$ for $10 \mathrm{~min}$ and the absorbance was recorded at $734 \mathrm{~nm}$. Results were expressed as Trolox equivalents antioxidant capacity (TEAC) in mmol of Trolox per $100 \mathrm{~g}$ dry weight of rice bran.

\subsection{Statistical analysis}

Results were expressed as mean \pm SD. Data of each experiment were statistically analyzed using SAS version 6.12. One way analysis of variance (ANOVA) and the Duncan's Multiple Range Test (DMRT) were used to determine the differences among treatment means.

\section{Results}

3.1 Nutritional properties of selected Sri Lankan traditional rice

The nutritional properties of the selected Sri Lankan traditional rice varieties are given in Table 1 and 2 respectively. Significant differences $(\mathrm{P}<0.05)$ were observed among the varieties for the tested nutritional properties (Table 1 and 2). Maa Wee had the highest $(\mathrm{P}<0.05)$ crude protein $(11.16 \pm 0.37 \%)$ and sugar $(5.86 \pm 0.15 \%)$ contents while Heeneti had the highest $(\mathrm{P}<0.05)$ ash $(1.68 \pm$ $0.02 \%)$ content among the varieties tested. Highest $(\mathrm{P}<0.05)$ dietary fiber content was observed for the variety Suwadal $(6.28 \pm 0.06 \%)$ while both Suwadal (3.28 $\pm 0.04 \%)$ and Kurulu Thuda (3.14 $\pm 0.06 \%)$ contained the highest fat contents. Among the varieties tested Suwadal had the least available carbohydrate $(80.80 \pm 0.36 \%)$ content. Fatty acid composition of bran oils of selected rice varieties is given in Table 2 . Kurulu Thuda rice variety exhibited the highest oleic (49.48 $\pm 0.58 \%)$ and palmitic acid $(22.16 \pm 0.89 \%)$ contents while Maa Wee showed the highest linoleic acid $(31.86 \pm 0.76 \%)$ content. The most predominant fatty acid in all rice bran oils was oleic acid (Table 2).

\subsection{Antioxidant properties of selected Sri Lankan traditional rice}

The antioxidant properties of brans of selected Sri Lankan traditional rice varieties are given in Table 3. Significant differences $(\mathrm{P}<0.05)$ were observed for the antioxidant properties among rice varieties and between red and white rice tested in this study. 
Table 1. Nutritional properties of whole grains of selected Sri Lankan traditional rice

\begin{tabular}{lrcrrr}
\hline $\begin{array}{l}\text { Nutritional parameter } \\
\text { (\% dry basis) }\end{array}$ & \multicolumn{5}{c}{ Rice variety } \\
\cline { 2 - 6 } Moisture & \multicolumn{1}{c}{ Suwadal } & Heeneti & Nilkanda & Kurulu Thuda & Maa Wee \\
Crude Protein & $13.84 \pm 0.07^{\mathrm{a}}$ & $13.59 \pm 0.02^{\mathrm{b}}$ & $13.81 \pm 0.06^{\mathrm{a}}$ & $13.65 \pm 0.12^{\mathrm{ab}}$ & $13.36 \pm 0.04^{\mathrm{c}}$ \\
Crude ash & $8.09 \pm 0.35^{\mathrm{b}}$ & $8.10 \pm 0.09^{\mathrm{b}}$ & $7.80 \pm 0.02^{\mathrm{b}}$ & $8.44 \pm 0.13^{\mathrm{b}}$ & $11.16 \pm 0.37^{\mathrm{a}}$ \\
Crude fat & $1.55 \pm 0.01^{\mathrm{b}}$ & $1.68 \pm 0.02^{\mathrm{a}}$ & $1.54 \pm 0.01^{\mathrm{b}}$ & $1.50 \pm 0.04^{\mathrm{b}}$ & $1.55 \pm 0.01^{\mathrm{b}}$ \\
Total Dietary fibre & $3.28 \pm 0.04^{\mathrm{a}}$ & $2.89 \pm 0.04^{\mathrm{b}}$ & $2.78 \pm 0.13^{\mathrm{b}}$ & $3.14 \pm 0.06^{\mathrm{a}}$ & $2.78 \pm 0.10^{\mathrm{b}}$ \\
Available carbohydrates & $6.28 \pm 0.06^{\mathrm{a}}$ & $4.96 \pm 0.08^{\mathrm{b}}$ & $5.13 \pm 0.14^{\mathrm{b}}$ & $4.88 \pm 0.06^{\mathrm{b}}$ & $2.68 \pm 0.17^{\mathrm{c}}$ \\
Sugar & $80.80 \pm 0.36^{\mathrm{b}}$ & $82.37 \pm 0.11^{\mathrm{a}}$ & $82.74 \pm 0.04^{\mathrm{a}}$ & $82.04 \pm 0.16^{\mathrm{a}}$ & $82.23 \pm 0.69^{\mathrm{a}}$ \\
\hline Results expressed & $2.28 \pm 0.04^{\mathrm{d}}$ & $2.70 \pm 0.09^{\mathrm{bc}}$ & $2.41 \pm 0.26^{\mathrm{cd}}$ & $2.92 \pm 0.15^{\mathrm{b}}$ & $5.86 \pm 0.15^{\mathrm{a}}$ \\
\hline
\end{tabular}

Results expressed as mean \pm SD ( $n=3)$. Crude fat, crude protein, crude ash, total dietary fiber, available carbohydrate and sugar contents are expressed as \% dry basis. Mean values in a row superscripted by different letters are significantly different at $\mathrm{P}<0.05$.

Table 2. Fatty acid profile of bran oils of selected Sri Lankan traditional rice

\begin{tabular}{lccc}
\hline \multirow{3}{*}{ Rice variety } & \multicolumn{3}{c}{ Fatty acid \% } \\
\cline { 2 - 4 } & $\begin{array}{c}\text { Palmitic acid } \\
\mathbf{( C 1 6 : 0 )}\end{array}$ & $\begin{array}{c}\text { Oleic acid } \\
\text { (C18:1) }\end{array}$ & $\begin{array}{c}\text { Linoleic acid } \\
\text { (C18:2) }\end{array}$ \\
\hline Suwadal & $19.67 \pm 0.21^{\mathrm{c}}$ & $46.66 \pm 0.65^{\mathrm{b}}$ & $30.43 \pm 0.68^{\mathrm{a}}$ \\
Heeneti & $20.09 \pm 0.41^{\mathrm{c}}$ & $47.64 \pm 0.91^{\mathrm{b}}$ & $27.86 \pm 0.51^{\mathrm{b}}$ \\
Nilkanda & $19.56 \pm 0.34^{\mathrm{c}}$ & $46.70 \pm 0.24^{\mathrm{b}}$ & $27.72 \pm 0.37^{\mathrm{b}}$ \\
Kurulu Thuda & $23.50 \pm 0.75^{\mathrm{a}}$ & $49.48 \pm 0.58^{\mathrm{a}}$ & $22.16 \pm 0.89^{\mathrm{c}}$ \\
Maa Wee & $21.83 \pm 0.23^{\mathrm{b}}$ & $42.76 \pm 0.75^{\mathrm{c}}$ & $31.86 \pm 0.76^{\mathrm{a}}$ \\
\hline
\end{tabular}

Results expressed as mean $\pm \mathrm{SD}(\mathrm{n}=3)$. Mean values in a column superscripted by different letters are significantly different at $\mathrm{P}<0.05$.

Table 3. Antioxidant properties of brans of selected Sri Lankan traditional rice

\begin{tabular}{llllll}
\hline $\begin{array}{l}\text { Antioxidant } \\
\text { property }\end{array}$ & \multicolumn{4}{c}{ Rice variety } \\
\cline { 2 - 5 } & Suwadal & Heeneti & Nilkanda & Kurulu Thuda & Maa Wee \\
\hline FRAP & $2.47 \pm 0.17^{\mathrm{d}}$ & $5.89 \pm 0.63^{\mathrm{b}}$ & $5.87 \pm 0.08^{\mathrm{b}}$ & $6.79 \pm 0.42^{\mathrm{a}}$ & $4.91 \pm 0.75^{\mathrm{c}}$ \\
ABTS & $0.58 \pm 0.02^{\mathrm{e}}$ & $10.62 \pm 0.28^{\mathrm{c}}$ & $11.12 \pm 0.11^{\mathrm{b}}$ & $13.13 \pm 0.28^{\mathrm{a}}$ & $9.02 \pm 0.16^{\mathrm{d}}$
\end{tabular}

Results presented as mean \pm standard deviation $(\mathrm{n}=3)$ on dry weight basis. ABTS radical scavenging activity: mmol Trolox /100 g bran; Ferric reducing antioxidant power (FRAP): mmol $\mathrm{FeSO}_{4} / 100 \mathrm{~g}$ bran. Mean values in a row superscripted by different letters are significantly different at $\mathrm{P}<0.05$. 
Mean FRAP and ABTS radical scavenging activity of rice varieties ranged from 2.47 $\pm 0.17-6.79 \pm 0.42 \mathrm{mmol} \mathrm{FeSO}_{4} / 100 \mathrm{~g}$ bran and $0.58 \pm 0.02-13.13 \pm 0.28 \mathrm{mmol}$ Trolox /100 g bran respectively. Kurulu Thuda variety exhibited highest activities for both FRAP and ABTS radical scavenging antioxidant properties while Suwadal had the lowest. The order of potency of brans of selected rice for FRAP and ABTS were Kurulu Thuda $>$ Heeneti $=$ Nilkanda > Maa Wee > Suwadal and Kurulu Thuda $>$ Nilkanda $>$ Heeneti $>$ Maa Wee $>$ Suwadal respectively.

\section{Discussion}

Whole grains are rich sources of variety of nutrients and phytochemicals such as antioxidants, dietary fibre, vitamins, minerals and fat (Slavin, 2003; Jones, 2006; Dykes \& Rooney, 2007; Okarter \& Liu, 2010). Most of these nutrients and phytochemicals are present in the outer layers of the grain and thus grain refining process leads to significant loss of these components (Slavin, 2003). Epidemiological studies have clearly shown that regular consumption of whole grains rather than the refined grains has variety of health benefits. They are important in prevention and dietary management of variety of chronic diseases such as cancer, diabetes, cardiovascular diseases, inflammatory diseases and obesity (Slavin, 2003; Jones, 2006; Dykes \& Rooney, 2007; Okarter \& Liu, 2010). Rice is the dietary staple of half of the world's population including Sri Lanka (Juliano, 1985; Juliano, 2003). In this study whole grains of selected Sri Lankan traditional rice varieties were studied for a range of nutritional properties. Further, rice bran the outer layer of the rice grain was evaluated for antioxidant properties and bran oil was studied for the fatty acid profile.

As nutritional properties moisture, crude protein, crude ash, crude fat, total dietary fibre, available carbohydrates and sugar contents were studied. Moisture content of the rice grain has an important influence on the rice grain quality parameters such as keeping quality, milling quality and cooking and processing qualities of rice (Juliano, 2003). The grains can be stored only 2-3 weeks if moisture content is high (14$18 \%$ ) as it leads to growth of molds, rapid loss of viability and a reduction in eating quality (Juliano, 1985; Juliano, 2003). The moisture content of selected Sri Lankan traditional rice varieties were within range of moisture content required for safe storage of rice.

The protein content of rice grain is an important grain quality parameter (Juliano, 1985; Juliano, 2003). Protein contents of rice varieties in different regions of the world varied from 4.5 $15.9 \%$ in Asia (1626 rice varieties), 5.7 $11.4 \%$ in Australia (24 rice varieties), 4.5 - $14.8 \%$ in North America (190 rice varieties), 5.7 - 14.8\% in South America (301 rice varieties), 5.7 - 14.8\% in Europe (233 rice varieties) and $5.7-12.5 \%$ in Africa (300 rice varieties) (Kennedy \& Burlingame, 2003). Among the rice varieties tested in this study Ma Wee had high protein content. In Sri Lanka, rice is reported to provide nearly $40 \%$ of the recommended daily protein requirement (Sri Lanka grain and feed annual, 2006). Thus, consumption of especially whole grains of Ma Wee may be important for obtaining significant amount of recommended daily allowance of dietary protein for healthy individuals. 
Percentage ash is an indication of the mineral content of the rice grain. It is reported that ash content of the rice varies depending on the variety. Juliano (2003) showed that crude ash content of rice is in the range of $1.0-1.5 \%$ at $14 \%$ moisture content (dry weight basis it is in the range of $1.16-1.74 \%)$. Heinemann et al. (2005) reported that ash content of selected brown rice varieties of Brazil is in the range of $1.15-1.29 \%$. Sompong et al. (2011) observed that ash content of the studied rice were in the range of 0.82 $\pm 0.14-1.74 \pm 0.02 \%$. The selected rice varieties in the present study had the ash content in the range of $1.50 \pm 0.04-1.68 \pm$ $0.02 \%$ and thus findings are in agreement with the previous research findings.

Whole grain rice and especially rice bran is rich in fat. It is reported that rice contributes $3 \%$ to the dietary fat in developing countries (Anonymous, 2002). Present study showed that fat content of the selected rice varieties in the range of $2.78 \pm 0.13-3.28 \pm 0.04 \%$. Heinemann et al. (2005) showed that fat content of selected brown rice varieties was in the range of $2.37-3.02 \%$. Juliano (1985) has reported a little lower fat content for the brown rice than the findings of Heinemann et al. (2005) (1.6 - 2.8\% at $14 \%$ moisture content and 1.86 - 3.25 dry weight basis \%). Sompong et al. (2011) showed that fat content of selected rice varieties were in the range of $1.15 \pm 0.03$ $3.72 \pm 0.06 \%$. Thus findings of the present study are in agreement with the findings of the previous work. Fatty acid composition of rice bran has been studied by many researches worldwide and has shown that rice bran contains more mono and poly unsaturated fatty acids rather than the saturated fatty acids (Juliano, 1985; Juliano, 2003; Verma and Srivastav, 2017). In the present study we also observed that bran oils of Sri Lankan traditional rice had more oleic ( 2.2 fold) and linoleic (1.7 fold): unsaturated fatty acids compared to palmitic, a main saturated fatty acid in the rice bran.

Dietary fibers are non digestible polysaccharides and are associated with variety of health benefits. The dietary fiber content of whole grains of rice was reported to be in the range of $2.52 \pm 0.24$ - $4.51 \pm 1.60 \%$ (Sompong et al., 2011). Present study showed that Suwandal and Nilkanda varieties had high dietary fiber content indicating that consumption of whole grains of these rice varieties are important in obtaining significant amount of dietary fibers. Carbohydrate is the major component of the rice grain and it is important in obtaining significant amount of dietary energy. In Sri Lanka rice is reported to provide about $45 \%$ of the total calorie requirement for a person/day (Sri Lanka grain and feed annual, 2006). In this study the total available carbohydrate content of the tested varieties were in the range of 80.80 $\pm 0.36-82.74 \pm 0.04 \%$ and this is in agreement with the findings of Verma and Srivastav (2017). Thus, consumption of these varieties is important as the major source of dietary energy for Sri Lankans.

Antioxidants are compounds which can neutralize the harmful effects of free radicals thus the dietary intake of antioxidants especially naturally derived plant based antioxidants are encouraged. Pigmented rice bran is a good source of naturally occurring antioxidants (Laokuldilok et al., 2011; Sompong et al., 2011; Gunaratne et al., 2013; Premakumara et al., 2013). Studies conducted on antioxidant properties of traditional rice varieties of Sri Lanka has shown that red rice had significantly high 
antioxidant properties compared white rice (Gunaratne et al., 2013; Premakumara et al., 2013). This study also showed that brans of selected red rice had much greater antioxidant properties compared to bran of white rice variety Suwandal. Especially consumption of Kurulu Thuda with the bran is important in obtaining rice bran based natural antioxidants and therefore possibly important in dietary management of oxidative stress associated chronic diseases. However, further studies are required to support this statement. Considering all, both red and white selected traditional rice varieties of Sri Lanka had better nutritional properties. However, in terms of antioxidant properties red rice are far superior to the white rice.

\section{Conclusion}

It is concluded that nutritional and antioxidant properties vary significantly among the varieties and only antioxidant properties vary significantly between red and white rices. Among the rice varieties tested Kurulu Thuda had the highest antioxidant properties while for the nutritional properties highest activities for different parameters tested showed variation among the rice varieties

\section{Acknowledgement}

Financial assistance provided by the Treasury Sri Lanka (TG/11/37) is greatly acknowledged.

\section{References}

Abeysekera, W.K.S.M., Premakumara, G.A.S. (2016) Health food properties of traditional rice in Sri Lanka, Lambert Academic Publishing, Germany, pp. 1-392.

Abeysekera, W.K.S.M., Premakumara, G.A.S., Dar, A., Choudhary, M.I., Ratnasooriya, W.D., Kashif, M., Mudassar, C., Ali, S.R., Chandrasekharan, N.V. (2015a) Growth inhibition and cytotoxicity in human lung and cervical cancer cell lines and glutathione Stransferase inhibitory activity of selected Sri Lankan traditional red rice (Oryza sativa L.) brans, Journal of Food Biochemistry 39: 585593.

Abeysekera, W.K.S.M., Premakumara, G.A.S., Ratnasooriya, W.D., Choudhary, M.I., Dalvandi, K., Chandrasekharan, N.V. (2015b) Antidiabetic related health food properties of traditional rice (Oryza sativa L.) in Sri Lanka, Journal of Coastal Life Medicine 3 (10): 815820.

Anonymous, (2011) Biology of Oryza sativa L. (Rice), Department of Biotechnology, Ministry of Science and Technology and Ministry of Environment and Forests, Government of India, $1-9 \mathrm{p}$.

Anonymous, (2002) Nutritional contribution of rice: impact of biotechnology and biodiversity in rice-consuming countries, The international rice commission, Twentieth Session, Bangkok, Thailand.

Asp, N.G., Johansson, C.G., Hallmer, H., Siljestrom, M. (1983) Rapid Enzymatic Assay of Insoluble and Soluble Dietary Fiber, Journal of Agricultural and Food Chemistry 31: 476482.

Association of Official Analytical Chemists (AOAC) (2000) 19th edition, Washington DC.

Benzie, I.F.F., Szeto, Y.T. (1999) Total antioxidant capacity of teas by the ferric reducing/antioxidant power assay, Journalof Agricultural and Food Chemistry 47 (2): 633636. 
Dharmasena, P.B. (2010) Traditional rice farming in Sri Lanka, Economic review, 48-53 p.

Dogara, A.M., Jumare, A.I. (2014) Origin, Distribution and Heading date in Cultivated Rice, International Journal of Plant Biology and Research 2 (1):1008.

Dubois, M., Gilles, K.A., Hamilton, J.K., Rebers, P.A., Smith, F. (1956) Colorimetric Method for Determination of Sugars and Related Substances, Analytical Chemistry 28 (3): 350356.

Dutta, A.K., Gope, P.S., Banik, S., Makhnoon, S., Siddiquee, M.A., Kabir, Y. (2012) Antioxidant properties of ten high yielding rice varieties of Bangladesh, Asian Pasific Journal of Tropical Biomedicine 2 (1): S99-S103.

Dykes, L., Rooney, L.W. (2007) Phenolic compounds in cereal grains and their health benefits, Cereal Foods World 52 (3): 105-111.

Fernandez, M.L., West, K.L. (2005) Mechanisms by which Dietary Fatty Acids Modulate Plasma Lipids, The Journal of Nutrition 135(9): 2075-2078.

Gunaratne, A., Wu, K., Li, D., Bentota, A., Corke, H., Cai, Y-Z. (2013) Antioxidant activity and nutritional quality of traditional red-grained rice varieties containing proanthocyanidins, Food Chemistry 138: 1153-1161.

Heinemann, R.J.B., Fagundes, P.L., Pinto, E.A., Penteado, M.V.C., Lanfer-Marquez, U.M. (2005) Comparative study of nutrient composition of commercial brown, parboiled and milled rice from Brazil, Journal of Food Composition and Analysis 18: 287-296.

International Organization For Standardization, (1978) ISO 5509 Animal and vegetable fats and oils, Preparation of methyl esters of fatty acids.
International Organization For Standardization, (1990) ISO 5508 Animal and vegetable fats and oils, Analysis by gaschromatography of methyl esters of fatty acids.

Jones, J.M. (2006) Grain-Based Foods and Health, Cereal Foods World 51(3):108-113.

Juliano, B.0. (1985) Rice Chemistry and Technology, American Association of Cereal Chemists, Inc, St. Paul, Minnesota, USA.

Juliano, B.0. (2003). Rice Chemistry and Quality. Island Publishing House, Manila, Philippines.

Kennedy, G., Burlingame, B. (2003) Analysis of food composition data on rice from a plant genetic resource perspective, Food Chemistry, 80: 589-596.

Khush, G.S. (1997) Origin, dispersal, cultivation and variation of rice, Plant Molecular Biology 35:25-34.

Laokuldilok, T., Shoemaker, C.F., Jongkaewwattana, S., Tulyathan, V. (2011) Antioxidants and antioxidant activity of several pigmented rice brans, Journal of Agricultural and Food Chemistry 59 (1): 193199.

Okarter, N., Liu, R. H. (2010) Health benefits of whole grain phytochemicals, Critical Reviews in Food Science and Nutrition 50:193-208.

Orsavova, J., Misurcova, L., Ambrozova, J.V., Vicha, R., Mlcek, J. (2015) Fatty acids composition of vegetable oils and its contribution to dietary energy intake and dependence of cardiovascular mortality on dietary intake of fatty acids, International Journal of Molecular Sciences 16: 1287112890. 
Premakumara, G.A.S., Abeysekera, W.K.S.M., Ratnasooriya, W.D., Chandrasekharan, N.V., Bentota, A.P. (2013) Antioxidant, antiamylase and anti-glycation potential of brans of some Sri Lankan traditional and improved rice (Oryza sativa L.) varieties, Journal of Cereal Science 58 (3): 451-456.

Rajapakse, R.M.T., Sandanayake, C.A., Pathinayake, B.D. (2000) Foot prints in rice variety improvement and its impact on rice production in Sri Lanka, Annual Symposium of the Department of Agriculture, Department of Agriculture, Sri Lanka, 2: pp 423-433.

Ranganna, S. (1986) Hand book of Analysis and Quality Control for Fruit and Vegetable Products, Second Edition, New Delhi, Tata McGraw-Hill Education, 1112 p.

Re, R., Pellegrini, N., Proteggente, A., Pannala, A., Yang, M., Rice-Evans, C. (1999) Antioxidant activity applying an improved ABTS radical cationdecolorization Assay, Free Radical Biology and Medicine 26: 1231-1237.

Rice Market Monitor, FAO. (2016) Trade and Markets Division, Food and Agriculture Organization of the United Nations, 1-34 p.

Slavin, J. (2003) Why whole grains are protective: biological mechanisms, Proceedings of the Nutrition Society 62: 129134.

Sompong, R., Siebenhandl-Ehn, S., LinsbergerMartin, G., Berghofer, E. (2011) Physicochemical and antioxidative properties of red and black rice varieties from Thailand, China and Sri Lanka, Food Chemistry 124: 132-140.

Sri Lanka grain and feed annual, (2006) USDA Foreign Agricultural Service, Global Agriculture Information Network.

Suriyagoda, L.D.B., Thilakarathne, R.M.M.S., Nissanka, S.P., Samita, S. (2011) Morphological variation in selected rice (Oryza sativa L.) germplasm of Sri Lanka,
Journal of the National Science Foundation of Sri Lanka 39(2): 129-137.

Verma, D.K., Srivastav, P.P. (2017) Proximate composition, Mineral Content and Fatty Acids Analysis of Aromatic and Non-aromatic Indian Rice, Rice Science 24(1): 21-31.

Wickramasinghe, H.A.M., Noda, T. (2008) Physicochemical properties of starches from Sri Lankan rice varieties, Food Science and Technology Research 14(1): 49-54. 